\title{
Densimetric exchange flow in rectangular channels
}

\section{I.-DEFINITIONS, REVIEW AND RELEVANCE TO MODEL DESIGN}

\author{
BY D.I.H. BARR, \\ DEPARTMENT OF GIVIL ENGINEERING \\ THE ROYAL COLLEGE OF SCIENGE AND TEGHNOLOGY, GLASGOW
}

\begin{abstract}
This series of papers concerns investigations of the phenomenon of exchange flow in water; in particular the situations where the two masses of water at different densities are contained in horizontal rectangular channels. It is considered (Barr 1958) that the correct scaling of hydraulic models involving internal spread phenomena can only be determined in the knowledge of the characteristics and mechanism of exchange flow. The type of problem particularly in mind is the prediction of the extent of recirculation of cooling water discharged from thermal power stations sited on estuaries or tidal rivers. The continuing use of such models in Scotland (Barr, 1958; Smith, 1962) is considered to have justified the step by step approach made to the problem. First the overall pattern of advance of the fronts of exchange flow was studied. From these observations, and making use of the extensive and valuable experimental studies of Keulegan $(1957,1958)$ a design method for heat dissipation models has been devised, and has, in fact, been applied to three large model studies (Smith 1962, Barr, $1963 \mathrm{c}$ ).

In this paper (I) exchange flow is introduced and reviewed and some new experimental results given. These include, it is thought for the first time, some details of "dam burst analogy" exchange flow. An attempt is made to explain the necessary compromising approach of those who practice the science-or art-of hydraulic modelling, and to apply this approach to the case of heat dissipation models.
\end{abstract}

\section{LOCK AND DAM BURST ANALOGY CASES OF EXCHANGE FLOW}

\section{Introductory.}

A lock gate or other such division may separate bodies of still water of the same surface level but which differ slightly in density. While the opening of the gate may result in local disturbances, the predominant effect will be a continuing exchange pattern of flow which is caused by the density difference. The less dense water flows over the more dense and an equal underflow of the more dense water must pass the location of the gate in the opposite direction to the surface flow. Field observations of the phenomena have been made on various occasions, including those reported by Allen and Price (1959) at the Queen Elizabeth II Dock on the Mersey. The circumstance of a level bottom- ed rectangular open channel with an initially vertical density discontinuity, as shown in Figure $1 a$, has seemed the simplest case for attempts at analysis. A good approximation to this may be obtained in laboratory experiments by fitting a thin vertical cross barrier into slight grooves in the sides of a rectangular flume and thus initially separating the dissimilar bodies of water. If the barrier is lifted smoothly, relatively little local disturbance is caused. At small depths $(<0.75 \mathrm{ft}$, say) the time taken for remo$\mathrm{val}$ is slight in comparison with the time taken for exchange movements of the same order of travel length to develop, and little distortion of the flow patterns is thought to result from the approximation. The initial velocities $\left(V_{0}\right)$ of the tips or fronts of the underflow and overflow appcar uniform for a greater or lesser relative distance depending on the scale of the experiment, and are unaffacted by the channel width to depth ratio $(\mathrm{B} / \mathrm{H})$ except for extreme cases where $(\mathrm{B} / \mathrm{H})$ is well under 0.5 . Lock exchange flow is a convenient description for this type of cir- 
cumstance which has been described by Harleman (1961) as the classical problem in unsteady, nonuniform flow in two layered systems. Whether the latter part of this description is entirely suitable is discussed later in this series of papers (II).

Lock exchange flow has aroused spasmodic interest during the past thirty years or so; O'Brien and Cherno (1934), Yih (1957), Keulegan (1957) and Barr (1959) have described experimental studies, while Keulegan (1946) and Schijf and Schönfeld (1953) have given analytical approaches. It is one facet of the group of phenomena variously known as density currents, stratified flows, sub-surface flows or internal flows. The existence of parallels between sub-surface and free surface hydraulic occurences has been stressed by various writers, notably Knapp (1942), Keulegan (1950) and more recently, Harleman (1961). It is, however, important to remember that in practical circumstances small density difference phenomena are normally observed as between miscible fluids; fresh and salt or warmer and colder water, warmer and colder air, or between air and other gases (Bakke, 1959). In the laboratory miscible liquids may be used, as in the exchange flow studies mentioned above, or immiscible liquids as in the experiments described by Long (1953-1955) where the practical circumstances in mind were meteorological. The experiments of Abbot (1961) relating to the spread of oil or petrol from a holed tanker and of Bata (1959), relating to exchange flow between petrol and water in the pipes of a fuel storage installation, are examples of the comparatively few cases where the liquids in both "model" and "prototype " are immiscible. It is not unlikely that the parallelism between free surface and subsurface phenomena may be rather more marked in the case of immiscible liquids; it would certainly be difficult to obtain, say, such a well formed internal hydraulic jump in miscible liquids as has been observed in immiscible liquids. On the other hand very much of the interest of exchange flow is related to the mixing processes, and there is in this respect, as shall be shown, little similarity between exchange flows in the miscible and the immiscible cases.

\section{Densimetric Froude and densimetric Froude- Reynolds numbers, $\mathscr{F}_{\triangle}$ and $\overline{\mathscr{F H}_{\triangle}} \mathfrak{R}$.}

The effective gravitational constant, $g^{\prime}$, for an immersed liquid (or body) is $g \cdot\left(\rho_{1}-\rho_{2}\right) / \rho_{1}$ where $\rho_{1}$ and $\rho_{2}$ are the densities of the immersed and the surrounding liquid respectively. If $\rho_{1}-\rho_{2}=\Delta \rho$ is small the approximation:

$$
g^{\prime}=g \Delta \rho / \rho
$$

can be used (i.e. $p \fallingdotseq p_{1} \fallingdotseq p_{2}$ ). By substituting $g^{\prime}$ for $g$ in the standard Froude number, $\mathscr{g}$ :

$$
\mathscr{g}=\mathrm{V} \sqrt{g \mathrm{~L}}
$$

where $L$ and $V$ are characteristic length and velocity respectively), the densimetric Froude number $\mathscr{y}^{\prime} \Delta=V \sqrt{g^{\prime} \mathrm{H}}$, is obtained. $H$ is the depth of the density discontinuity at the start of an exchange flow (Fig. 1), and the total depth in lock exchange flow: as exchange flow is being considered it is best to here use $\mathrm{H}$, as being the logical characteristic length. The densimetric Froude number is, in effect, the "overall" Richardson number (Ellison and Turner 1959) $\left(\mathscr{F}_{\triangle}=-\mathrm{Ri}^{-1 / 2}\right)$ although the lines of reasoning which led to the original formulation of these parameters are somewhat different (Barr, 1963), $\mathrm{V}_{\Delta}=\sqrt{g^{\prime} \mathrm{H}}$, the densimetric velocity, is a convenient characteristic velocity, particularly for lock exchange flow studies where the differing liquids can be regarded as mutually immersed.

Since it is desired to find criteria of similarity between various compared systems, it is convenient to use the terms prototype and model although not intending that an actual hydraulic model necessarily be imagined. In free surface hydraulics and using water in both prototype and model, the simultaneous use of both the Froude number criteria (Reynolds number $\mathfrak{K}=\mathrm{VH} / \nu$ where $\nu$ is the kinematic viscosity) leads to a model of the same size as the prototype. However the requirements of both densimetric Froude and Reynolds number criteria can be met together over a wide range of practical circumstances still with water as the liquid throughout.

Using subscripts $p$ and $m$ for prototype and model respectively-

$$
\frac{\mathrm{V}_{p}}{\mathrm{~V}_{m}}=\frac{\sqrt{g_{p}^{\prime} \cdot \mathrm{H}_{p}}}{\sqrt{g_{m}^{\prime} \cdot \mathrm{H}_{m}}}
$$

(Densimetric Froude number model criterion.)

$$
\frac{\mathrm{V}_{p}}{\mathrm{~V}_{m}}=\frac{\mathrm{H}_{m} \cdot \nu_{p}}{\mathbf{H}_{p} \cdot v_{m}}
$$

(Reynolds number model criterion.)

'io satisfy both:

or:

$$
\frac{\left(g_{p}^{\prime}\right)^{1 / 2} \cdot \mathrm{H}_{p}^{1 / 2}}{\left(g_{m}^{\prime}\right)^{1 / 2} \cdot \mathrm{H}_{m}^{1 / 2}}=\frac{\mathrm{H}_{m} \cdot v_{p}}{\mathbf{H}_{p} \cdot v_{m}}
$$

$$
\begin{gathered}
\frac{\left(g^{\prime}\right)^{1 / 2} \cdot H_{\eta}^{3 / 2}}{\nu_{p}}=\frac{\left(g_{m}^{\prime}\right)^{1 / 2} \cdot \mathrm{H}_{m}{ }^{3 / 2}}{\nu_{m}} \\
\overline{\mathscr{V}_{\Delta}} \boldsymbol{\mathcal { R }}=\left(g^{\prime}\right)^{1 / 2} \cdot \mathrm{H}^{3 / 2} / \nu \equiv \mathrm{V}_{\Delta} \cdot \mathrm{H} / \nu
\end{gathered}
$$

is the densimetric Froude-Reynolds number. Keulegan $(1957,1958)$ reporting on his exten- 

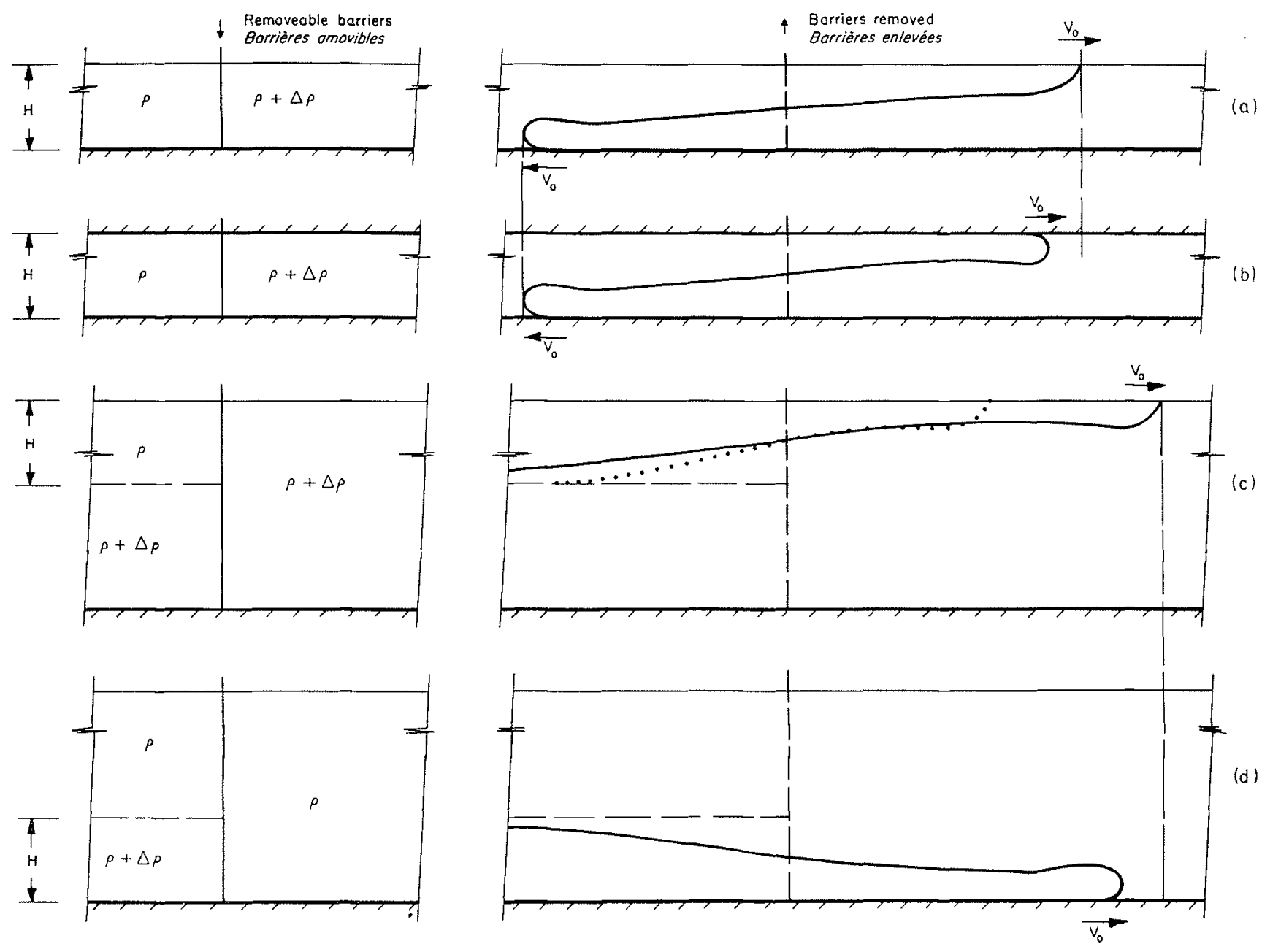

Fig. 1

Diagramatic illustrations of various exchange flow configurations (pure density current cases)

Représentation schématıque de divers profils d'écoulement d'échange (ces cas intéressent des courants de densité purs).

(a) Free surface lock exchange.

(b) Enclosed flume lock exchange.

(c) Dam-burst analogy exchange flow-free surface overflow.

(d) Dam-burst analogy exchange flow-underflow. a) Echange dans une écluse $\dot{a}$ surface libre.

b) Echange dans une écluse en canal couvert.

c) Ecoulement d'échange dans le cas représentant la rupture d'un barrage - écaulement «par cn-dessis» à surface libre.

d) Ecoulement d'échange dans le cas représentant la rupture d'un barrage - éconlement «par en-dessous». sive and valuable studies of exchange flow, first demonstrated the great usefulness of the concepts of densimetric velocity and densimetric Froude-Reynolds number. He used the nomenclature "densimetric Reynolds number $\left(\mathcal{R}_{\Delta}\right)$ " for the above dimensionless number where the densimetric Froude-Reynolds number $(\overline{\mathscr{T}} \Delta \mathcal{R})$ has been used here: the reasons for the change are given in Section 3 where reference is made

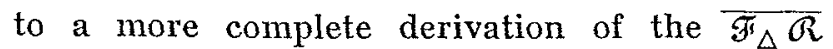
number which is given as an appendix (2) (Barr, $1963 b)$.

\section{Initial velocities.}

Figures 1 and 2 indicate the present state of knowledge of initial velocities, $V_{0},\left(V_{0}=\mathrm{K} . \mathrm{V}_{\triangle}\right)$ of various cases of exchange flow in a rectangular channel; Figure $1 a$ is the simple free surface case so far discussed (Keulegan 1957, Barr, 1959). The initial velocities of underflow and overflow differ by $12 \%$ over the range studied. If similar tests are carried out in a rectangular pipe (Fig. $1 b$ ) the coefficient obtained for both underflow and overflow are similar to those for the normal underflow (Barr, 1961). This latter 


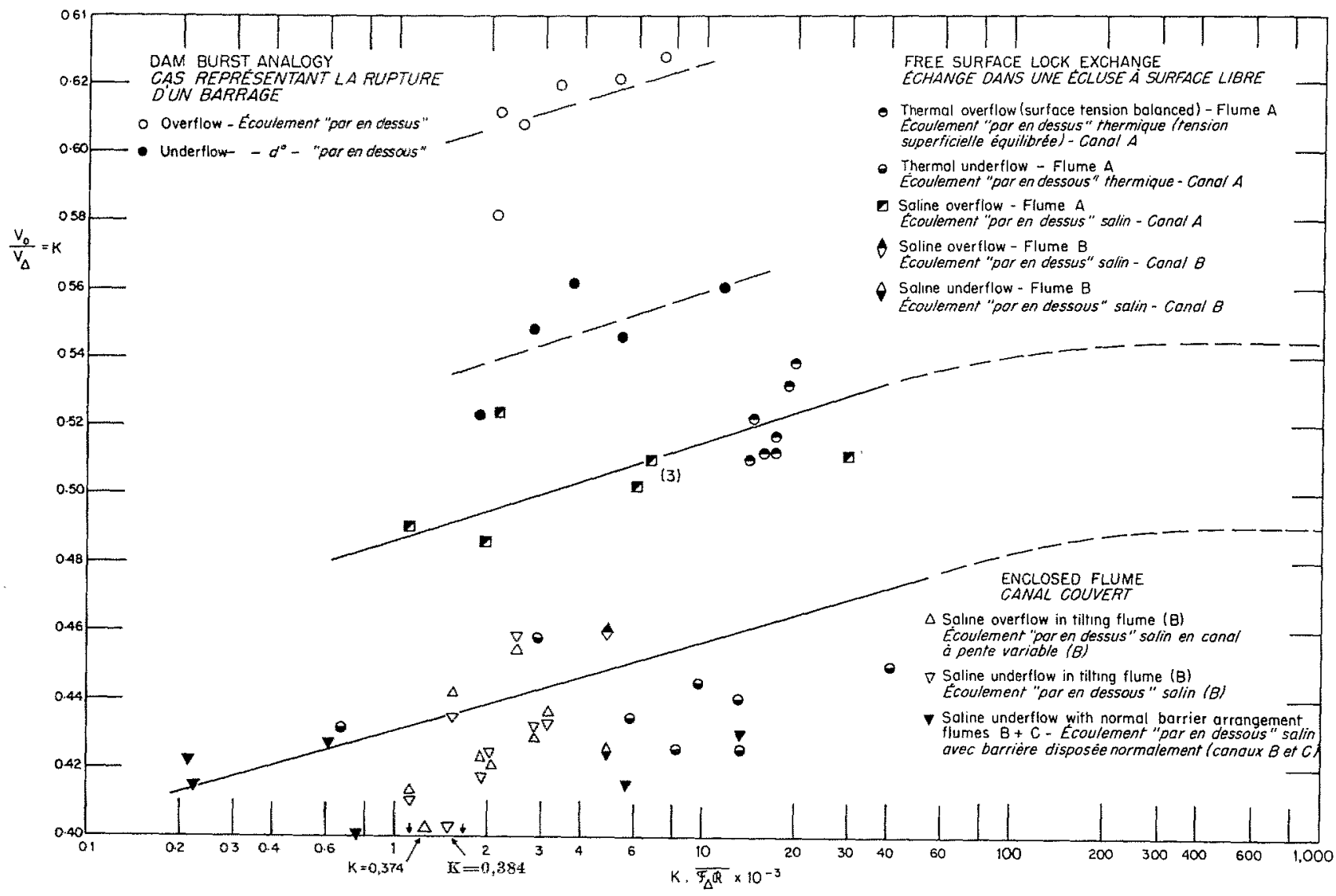

Fig. 2

Coefficient of proportionality for initial velocities of exchange flow configurations shown in Figure 1.

Coefficients de proportionalité correspondant aux vitesses initiales des schémas d'écoulement d'échange de la figure 1.
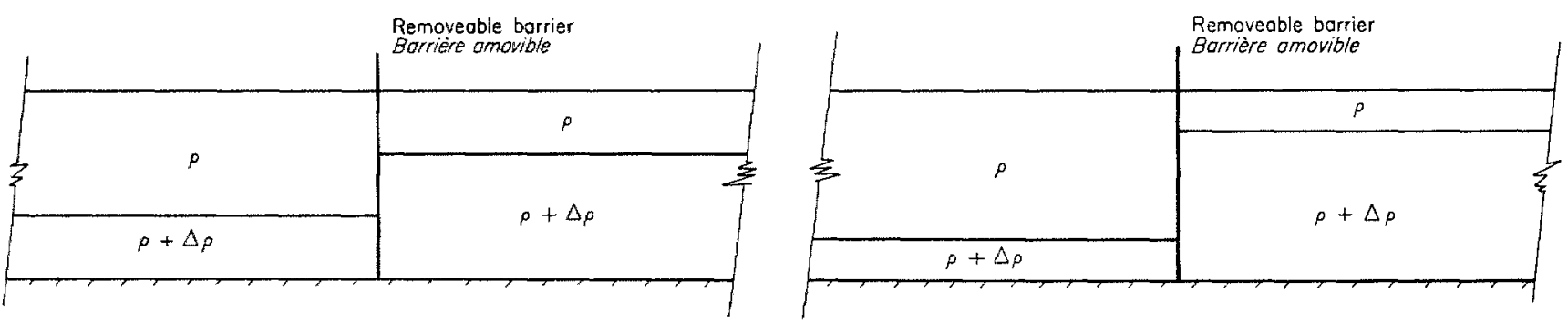

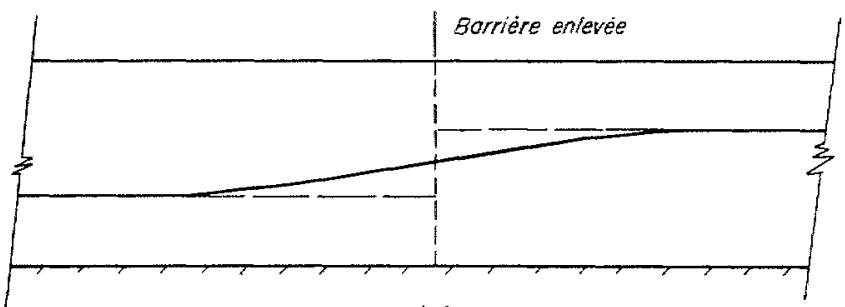

(a)

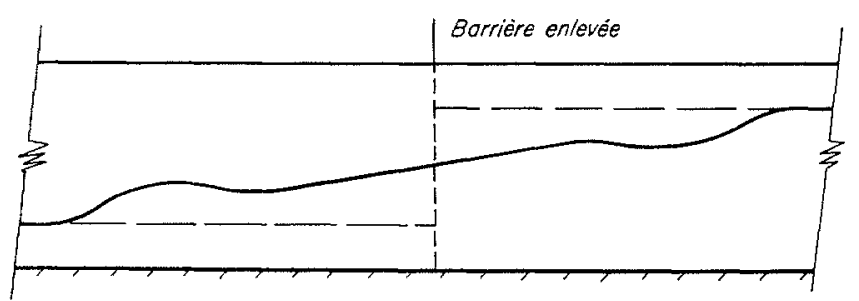

(b)

Frg. 3

Diagramatic illustrations of two further cases of exchange flow.

Représentation schématique de deux autres cas correspondant à des écoulements d'échange.

(a) Coupled "backwater" curves at interface.

(b) Intermediate case. a) «Courbes de remous» couplées à l'interface.

b) Cas intermédiaire. 

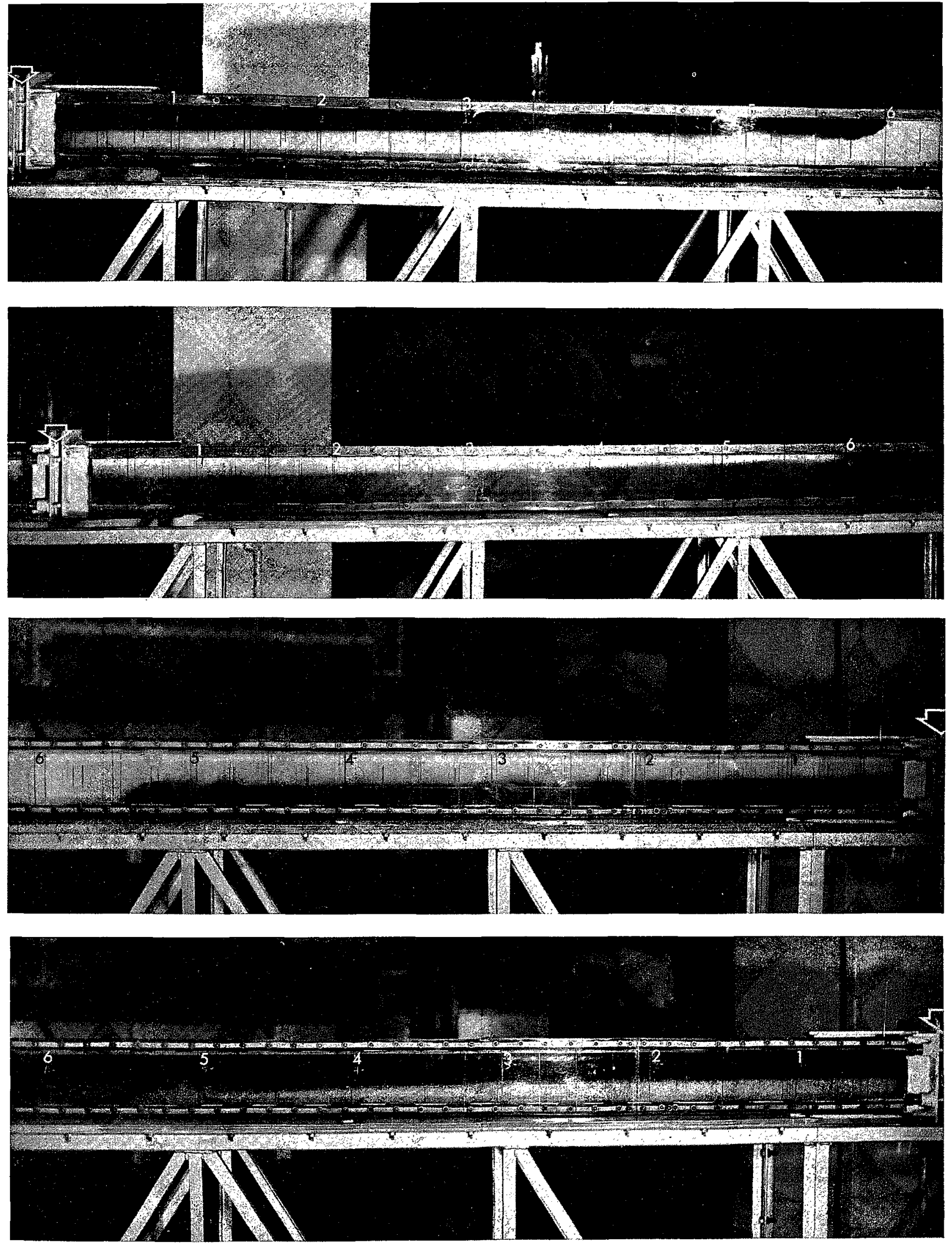

Fig. 4. - Views of lock exchange flow experiments (depth 4 in., breadth $41 / 8$ in. $\Delta_{Q} / Q=0.011$ ).

Photographies des essais sur les écoulements d'échange en écluse (profondeur $4 "$, largeur $41 / 8^{\prime \prime}, \Delta Q / Q=0,011$ ).

(a) Overflow, less dense water coloured.

(b) Overflow, more dense water coloured.

(c) Underflow, more dense water coloured.

(d) Underflow, less dense water coloured. a) Ecoulement «par en-dessus». Eau moins dense colorée.

b) Ecoulement «par en-dessus». Eau plus dense colorée.

c) Ecoulement "par en-dessous». Eau plus dense colorée.

d) Ecoulement «par en-desous». Eau moins dense colorée. 


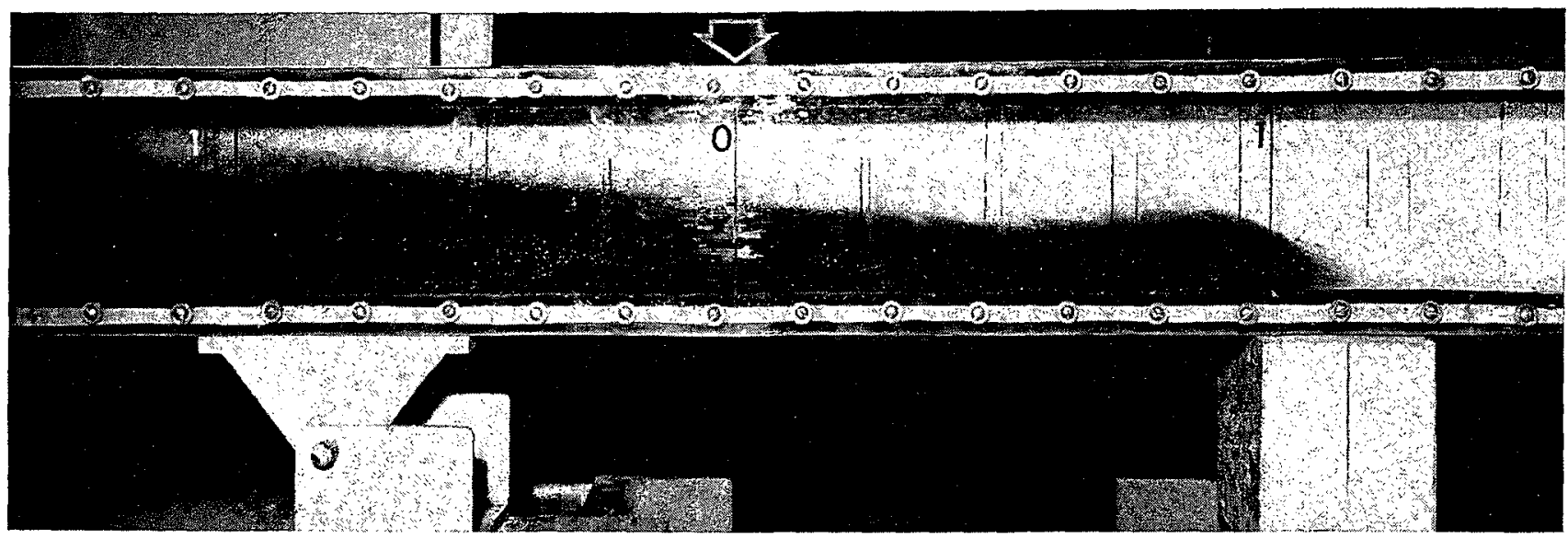

(a)

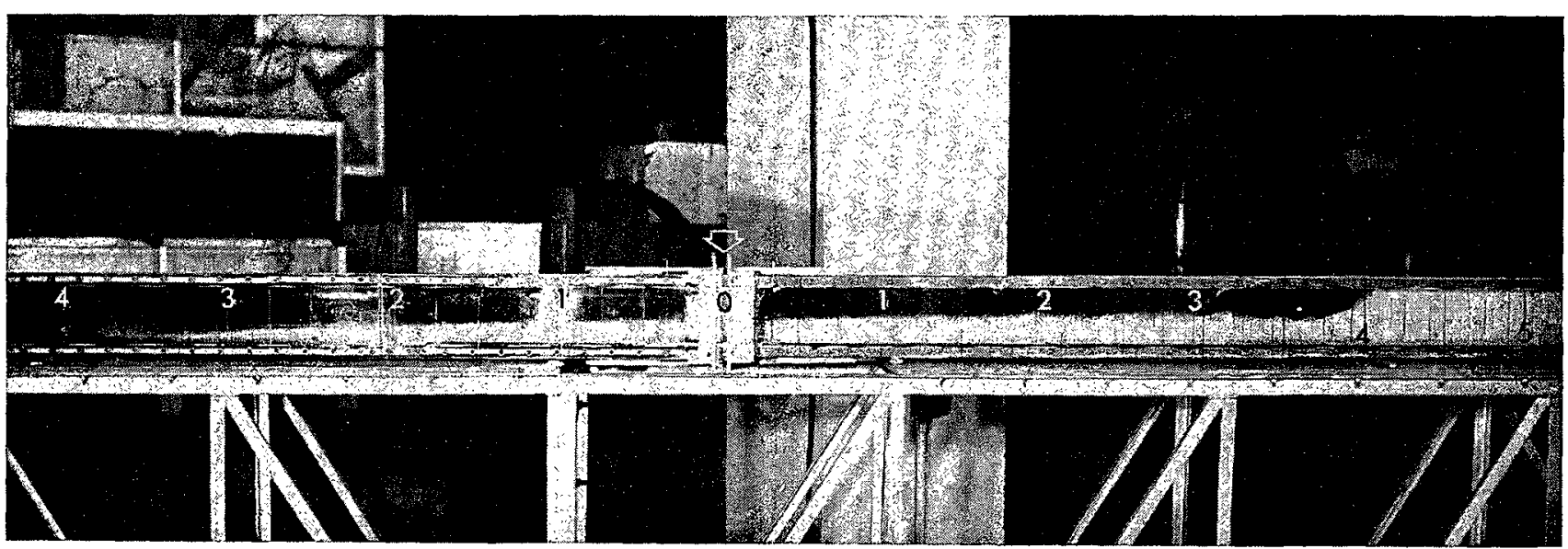

(b)

Fig. 5

Views of enclosed flume lock exchange flow experiments (depth and breadth both $41 / 8 \mathrm{in}$.)

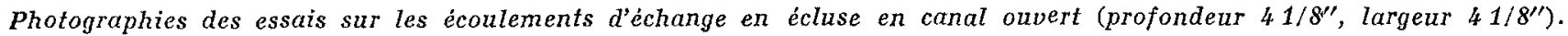

(a) Now initiated by tilting flume $\left(\Delta_{Q} / \varrho=0,0060\right)$.

(b) Flow initiated by removal of barrier $(\Delta \varrho / Q=0.0145)$.

circumstance will be termed the enclosed flume case of lock exchange. Also shown are results recently obtained during observations of damburst analogy exchange flow (Figure $1 c$ and Figure $1 d$ ) so called because of the similarity to the true dam burst phenomena. $H$ is again taken as the depth of the initially vertical interface. $V_{0}$ for the dam burst analogy cases is not, of course, independant of the $\mathrm{H}_{t} / \mathrm{H}$ ratio, where $\mathbf{H}_{t}$ is the total depth, but this seems to have little influence beyond values of this ratio of the order of 2. It will be seen that a similar increase in $\mathrm{K}$ was found between the free surface dam burst overflow and the dam burst underflow as exists between the overflow and the underflow of a) Ecoutement provoqué par l'inclinaison du canal $\left(\Delta_{\mathrm{Q}} / \mathrm{Q}=0,0060\right)$

b) Ecoulement provoqué par l'enlèvement d'une barrière $\left(\Delta_{\mathrm{Q}} / \mathrm{Q}=0,0145\right)$.

normal lock exchange flow. In the latter case both overflow and underflow are obtained in the same experiment (Fig. 1 a) while the dam burst analogy overflow (Fig. 1 c) and underflow (Fig. $1 d$ ) are both coupled with a type of backwater curve, the limit of extension of which is difficult to observe. Doubtless examples of dam burst analogy overflow could be observed in an enclosed flume and thence would be obtained the same values of $K$ as for equivalent underflows. Again, by arranging that the vertical interface extends to neither surface nor bottom of the flume, it is possible to couple the interfacial shifts as indicated in Figure $3 a$, or to obtain an intermediate case (Fig. $3 \mathrm{~b}$ ). 
Figure 4 shows photographs of free surface lock exchange flow, all taken when the extension ratio $\mathrm{L} / \mathrm{H}$ of the overflow was 18 in a 4 inch deep channel. The technique of colouring first the less dense and then the more dense water to show the limits of mixing was previously used by Keulegan (1957). Figure 5 shows photographs of enclosed flume lock exchange flow. In the experiment of Figure 5 a flow was initiated by tilting the flume through $90^{\circ}$, thus obviating the need for a harrier (Barr, 1961) while in that of Figure $5 b$ a normal barrier was used. The apparent difference between the completely similar overflow and underflow is caused by the dominance of the red dye, and this will be considered in paper II of the series.

The lock exchange underflow line on Figure 2 was first proposed tentatively by Keulegan (1957) and further results obtained by the author (Barr, 1959) tended to confirm the general trend of increasing values of $K$ with increasing $\overline{\mathscr{g}_{\Delta}} \mathcal{K}$. The large numbers of test points given previously are not again shown, but the opportunity has been taken to include some more recent évaluations.

\section{Diminution of front velocity.}

Further variations of coefficient of proportionality would be obtained in non-rectangular channels, or if a variation in channel shape were introduced at the barrier (Keulegan, 1958). In every case the velocity of the fronts falls away after some advance, the relative distance before this can be distinguished increasing with increasing values of $\overline{\mathscr{J}} \Delta$. This diminution of velocity has been studied experimentally in considerable detail by Keulegan $(1957,1958)$ for two restricted cases. It has been found to be

FiG. 6

View of dam-burst analogy overflow experiment in progress.

Essai en cours

avec écoulement «par en-dlessus», pour le cas représentant la rupture d'un barrage.
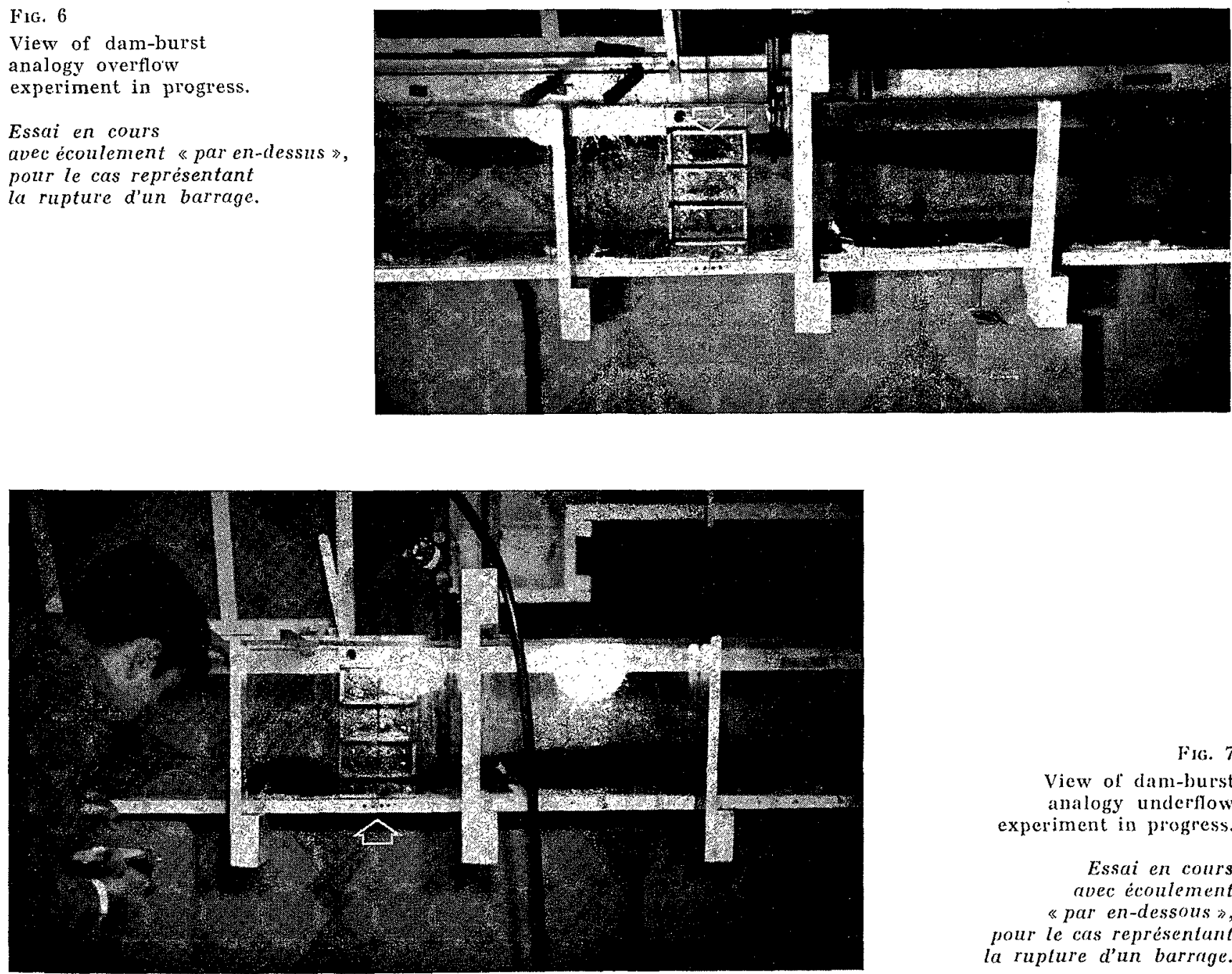

View of dam-burst analogy underflow experiment in progress.

Essai en cours abec écoulement «par en-dessous 》, pour le cas représentant la rupture d'un barrige. 


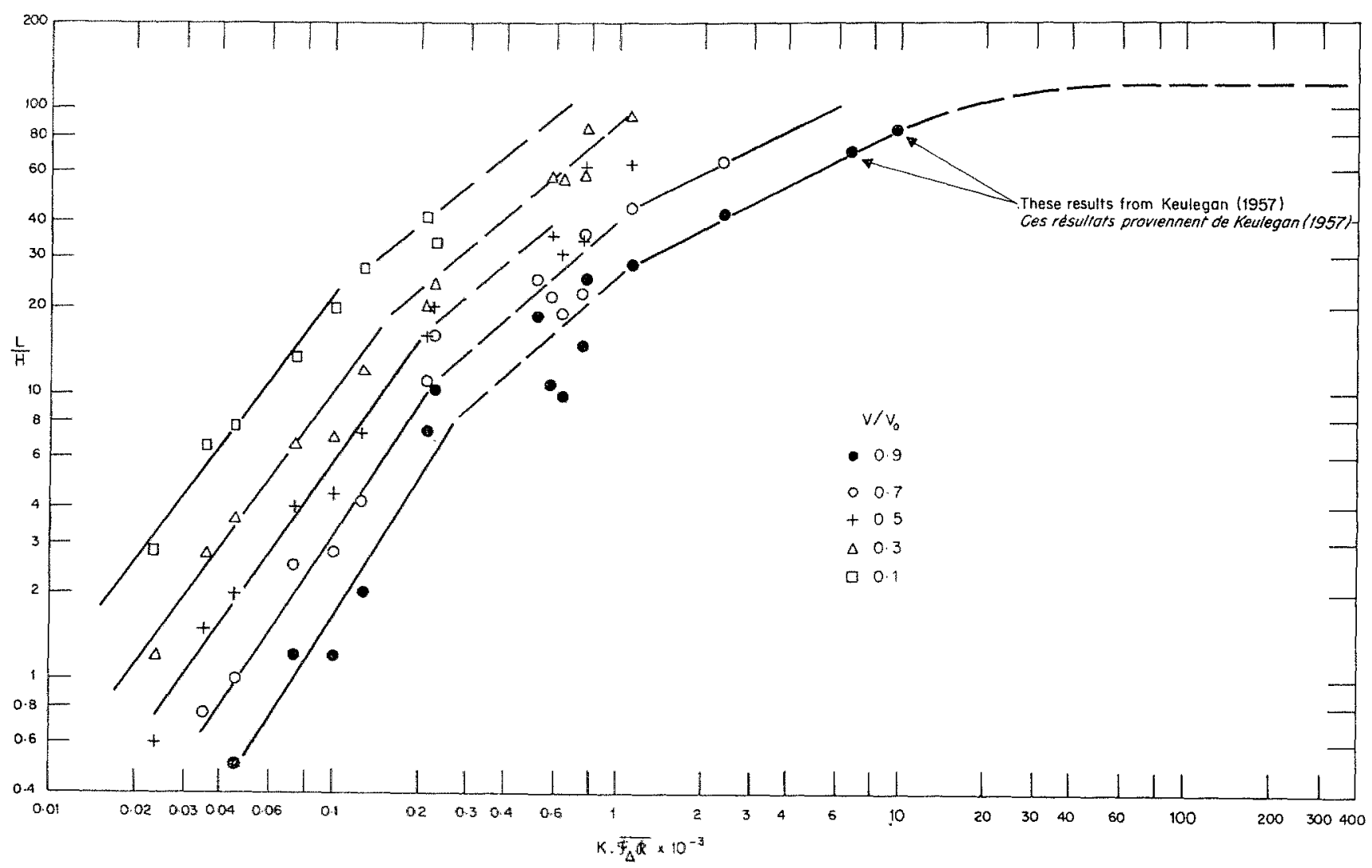

FIG. 8

Congruency diagram for underflow of lock exchange flow in "wide" flume with no reflection.

Schéma de congruence correspondant à l'e̊coulement «par en-clessous» d'un écoulement d'èchange dans un canal « de grande largeur» sans réflexions.

Notes (on Fig. 8):

(i) The practice of plotting both this diagram and the dingram showing variation of eoeffieient of proportionality for the initial velocities (Fig. 2) against $\mathrm{K} . \overline{F_{\triangle}} \bar{\Omega}$ was initiated by Dr. Keulegan. In the case of Figure 2 there are no real advantages and it is, in fact, somewhat irrational to plot the values of $\mathrm{K}$ for an underflow and an overflow, which can be obtained in the same experiment, against slightly different base valies. Howewer, the intention has been to compare with past work, and as $\mathrm{K}$ varies rather slowly with $\overline{\mathfrak{F}_{\Delta} \alpha}$ and thus with $K . \overline{9_{\Delta} \mathbb{R}}$ little harm results. If desired, it is simple to convert the "besl" lines as the author found expedient on one occasion (Barr, 1962).

Witlı regard to Figure 8 , there have been advantages in having arrangement whereby the slow variation of $K$ is allowed for in proportioning the diminution of velocity ratios. Again the diagram could be transferred to a $\overline{\mathbb{F}_{\Delta} \mathcal{R}}$ base but only by returning to the original plots of travel against time.

(ii) The results at very low values of $K . \overline{g_{2} \Omega}$ were obtained in a $1 / 4$ inch deep enclosed flume (i.e. two "underflows" oceurred) instead of in the normal open flume. However, the experiments is inevitably rather imperfect at this scale and this approximation is quite suitable to obtain the trend. It was necessary to assume that initial velocities as obtained from the extension of the lock exchange underfiow line on Fis. 2 momentarily existed.

alfected by the variations in configuration mentioned above, by channel width to depth ratio, and markedly by the presence of a reflection if
Note au sujet de la figure 8 :

a) La pratique suivant laquelle on trace, à la fois, le présent abarue, ef celui exprimant la variation du coefficient de proportionnalité correspondant anx vitesses initiales en fonction de $\mathrm{K} . \overline{\mathcal{F}_{\Delta}}{ }^{\Omega}, a$, été employée pour la première fais par le Dr. Keulegan. Le procédé ne présente aucun avantage réel dans le cas de la figure 2; en effet, il ne serait pas très rationnel de porter les valenrs de $\mathrm{K}$ correspondant $\dot{a}$ des écoulements \& par en-dessus » et «par en-dessous», qui peuvent être déterminées au cours d'une même expérience, en fonction de valeurs de base un tant soit peu différentes. Par contre, Pintention de l'auteur a été de confronter ses résultats avec ceux obtenus' au' cours d'études antérieures, et puisque la valeur de $\mathrm{K}$ varie assez

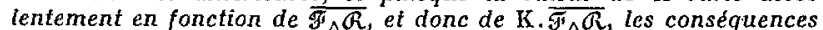
ne sont pas trop graves. On peut, si on le désire, aisément effectuer la conversion des courbes \& optimales *, ainsi que l'auteur a trouvé utile de le faire dans un cas (Barr, 1962).

En ce qui concerne la figure 8 , une disposition, dans laquelle on a tenu compte de la lente variation de $\mathrm{K}$ en proportionnant les rapports de diminution de vitesse, a présenté certnins avantages.

on pourrait également reporter l'abaque sur une base en $\overline{\mathcal{F}_{\triangle} \alpha}$, mais à condition de revenir aux graphiques initiaux du déplacement en fonction du tem $p$ s.

b) Les résultats correspondant aux trés faibles valeurs de $\mathrm{K} . \overline{\mathrm{TH}} \Delta$ ont été obtenus dans un canal couvert profond de $1 / 4^{\prime \prime}$ (c'est-ád-dire il s'est produit deux scoulements \& par en-dessous $»)$, a. la place du canal découvert normal. Mais l'expérience reste inévitablement assez imparfaite a cette échelle, et cette approximation suffit pour déterminer l'allure (la tendance) du phénomène. Il a fallu admettre l'existence momentanée des vitesses initiales obtenues par l'extension de la courbe de la figure 2, correspondant à l'écoulement a par endessous „ d'un échange en écluse.

either channel length is short (Keulegan, 1957; Barr, 1961). The simplest case for either lock or dam burst analogy exchange flow is for there 
to be sufficient breadth for the diminution of velocity to be unaffected by the sides; a breadth to depth ratio of about six being necessary (Keulegan, 1957), and for the length to depth ratio on both sides of the barrier to be sufficiently great for no reflection to occur within the period of the experiment. These will be referred to as the standard cases.

Keulegan used a plot of $\mathrm{L} / \mathrm{H}$ against $\mathrm{K} \cdot \overrightarrow{\mathscr{F}_{\triangle}} \overrightarrow{\mathcal{K}}$, where $L$ is the distance from the barrier by which the front velocity $\mathrm{V}$ has fallen to some proportion of $V_{0}$, to further illustrate the overall characteristics of exchange flow, and called this a congruency diagram. Figure 8 shows such a diagram, or rather the fragment so far available of that for the standard case of lock exchange underflow as shall be explained. First it should be said that if $\overline{\mathscr{F}_{\triangle}} \mathscr{\mathcal { R }}$ is a sufficient criterion of similarity in exchange flow, it should be possible to obtain data for the formulation of a congruency diagram for any selected configuration. That used principally by Keulegan was for the more dense water to be initially in a short length $\left(\mathrm{L}_{0}\right)$ of channel where $\mathrm{L}_{0}=7.2 \mathrm{H}$, and with the channel width $\mathrm{B}=\mathrm{H} / 2$. He carried out sufficient experiments at values of $K . \overline{\mathscr{F}} \triangle \mathcal{A}$ ranging from 600 to 200,000 to provide a very complete congruency diagram (within the aforesaid limits of K. $\overline{\left.\mathscr{F}_{\triangle} \mathscr{\mathcal { O }}\right)}$ for this configuration, and to demonstrate the sound basis of his approach. However the actual diagram is dominated by the side effects accruing from the small width to depth ratio and, more especially, by the inevitable presence of a reflection. Because of the width and, particularly, the length of flume required to allow for standard case observations except at small depths the author has so far been able to provide only the fragmentary congruency diagram shown in Figure 8.

The presumption, indicated in Figure 8, that the $\mathrm{L} / \mathrm{H}$ ratios for the various $\mathrm{V} / \mathrm{V}_{0}$ ratios becomes independant of $K \cdot \overline{F_{\triangle}} \mathcal{K}$ is based on the results of idealised channel and sea exchange flow experiments by Keulegan (1958). Figure 9 shows what is meant by the channel and sea configuration the more dense water being initially in the sea. Keulegan again used a relatively narrow arrangements $(B=H$ and $H / 2$ where $B$ is the breadth and $H$ the total depth) and obtained for the underflow initial velocities such that $\mathrm{K}$ averaged 0.57 . It must be presumed that this coefficient would vary slowly with $\overline{\mathscr{Y}_{\triangle} \mathcal{K}}$ for any given $\mathrm{H} / \mathrm{B}$ ratio, and depends considerably on the $H / B$ ratio. If the channel were very wide, the values for $K$ would be close to the values appropriate to the normal lock exchange underflow (up to about 0.49). However the most important aspect of the results

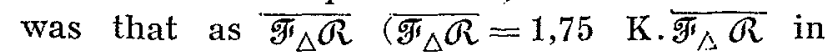

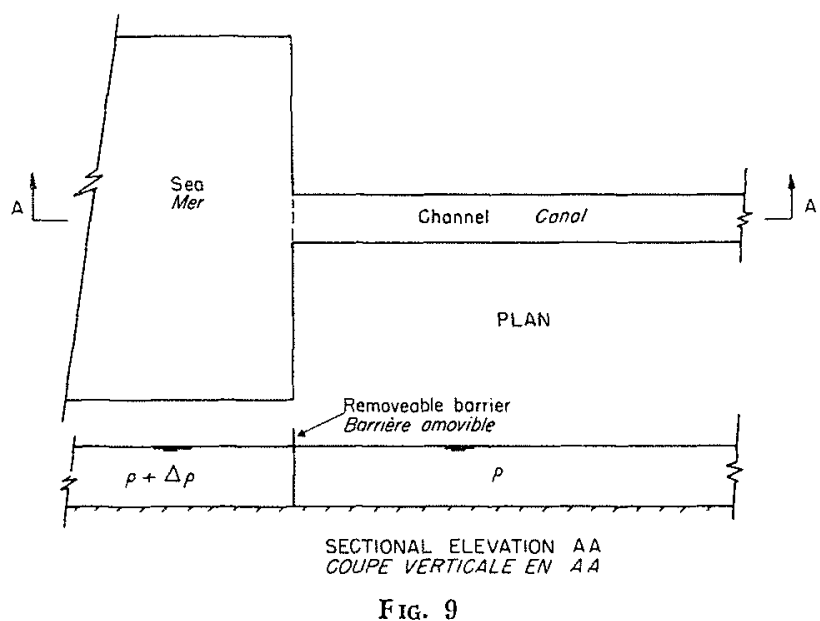

Channel and sea configuration.

Disposition «mer et canal»

this case) approached 45,000 the diminution of velocity pattern becomes independant of $\overline{\mathscr{J}_{\triangle}} \widehat{\mathcal{A}}$ as is shown in Figure 10.

The evidence so far available in no way contradicts the supposition that the general pattern of diminution of velocity for the lock exchange overflow is similar to that for the underflow. Figure 11 shows typical results obtained in the same experiment. Of course the scaling method mentioned in the synopsis, and explained in the next section, depends on the foregoing being true-heat dissipation models being concerned with warm overflows.

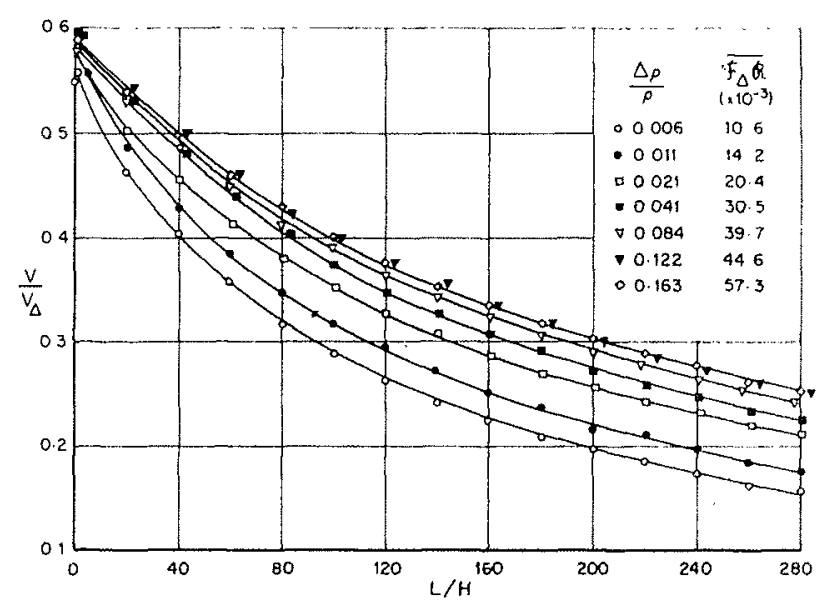

Fig. 10

Typieal results obtained by Keulegan (1958) for intrusion of saline underflow from "sea" into "freshwater" channel.

Résultats typiques obtenus par Keulegan (1958) pour la pénétration «par en-dessous» d'une langue salée, de la mer dans le canal « d'eau douce». 


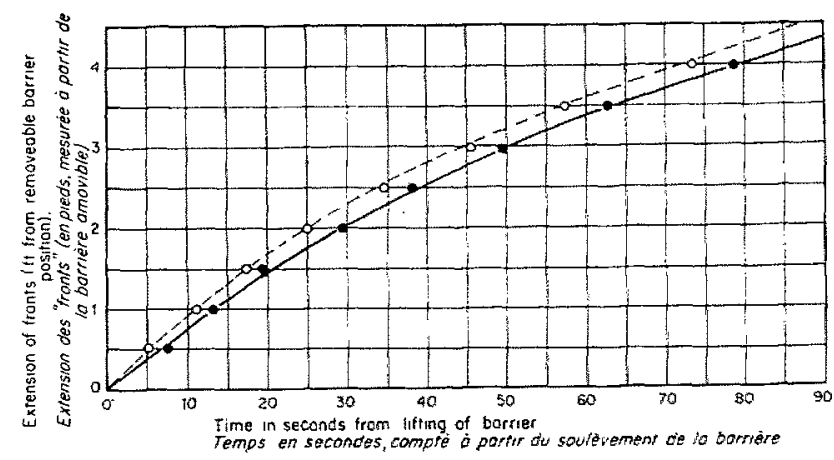

F1G, 11

Comparison of pattern of diminution of velocity of underflow and overflow obtained in typical lock exchange flow experiment.

Comparatson entre la diminution, d'une part, de la vitesse de l'écoulement "par en-dessous», et d'autre part, de celle de l'écoulement «par en-dessus », correspondant à une expérience-type sur l'écoulement d'ècharge en écluse.

\section{RELEVANCE OF EXCHANGE FLOW STUDIES TO HYDRAULIC MODEL DESIGN}

\section{Natural models involving exchange flow only.}

The present state of knowledge of initial velocities (Figs. 1 and 2) and of the pattern of diminution of front velocity as given by Keulegan for relatively narrow channels and shown on Figure 8 for the standard wide channel case of the lock exchange underflow allows the following general assessment of the model approach to be made. For natural models (i.e. those with full geometric similarity) there are two main possibilities.

(i) Information on initial velocities could be obtained from a model on the basis of the densimetric Froude criterion, and using the densimetric Froude-Reynolds criterion to check that Jittle diminution of velocity is likely within the period of observation. There would of course be little point in building a small scale model to examine the initial stages of lock exchange flow where the prototype is a rectangular channel because this case has been fairly well covered. However initial velocities in a large nonrectangular or in a non-prismatic channel could be fairly closely predicted from small scale model tests.

(ii) Once the pattern of diminution of velocity becomes of importance it would be best to adhere to the same densimetric Froude-Reynolds number in model as in prototype, and essential to make the model $\mathrm{K} . \overline{\mathscr{J}^{\prime}} \boldsymbol{\alpha}$ value of the order of $10^{\overline{5}}$ or greater. Assuming water of the same average viscosity be used in the model as obtains in the prototype, it can be seen that, because $\overline{\mathfrak{F} \triangle} \mathcal{R}$ is proportional to the 1.5 power of the depth and the 0.5 power of the density difference, a severe limitation is imposed on the scope of this approach. To make a reasonably small model (say 6 inches deep) of a lock and canal system where the prototype depth is $30 \mathrm{ft}$. and $\Delta \rho / \rho=0.027$ (fresh and salt water) would require an impossible density difference in the

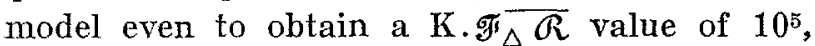
let alone that of the prototype. The point where the approximation $g^{\prime}=g \cdot \Delta \rho / \rho$ is no longer admissable has not been determined and would doubtless vary from case to case (Barr, $1963 \mathrm{~b}$ ). Any true model study is a compromise, the extent of the approximations allowable being initially a matter of judgement and later a factor in assessing the results. But the values of $\Delta_{p} / \rho=0.1$ and rather greater reached by Keulegan (Fig. 10) in his basic studies of the channel and sea configuration would appear to be a reasonable limit from both theoretical and practical standpoints.

\section{The device of exaggeration of the vertical scale in hydraulic models generally.}

The power of the method of models in solving problems in free boundary hydraulies has been demonstrated in thousands of successful studies. Model is again used in the restricted sense of an attempt at a smaller scale simulation of a large, and nearly always unique, natural or artificial hydraulic system: for instance, part of an estuary, or a large structure such as the overflow spillway of a dam. If the position is examined in more detail we find that where gravitational forces predominate and a fixed containing boundary obtains, consistant agreement is found between model and prototype, so long as various well established precautions are taken in the design and use of the model. Where frictional forces have the same order of influence as the gravitational forces, success has also been met with, but to a lesser extent; in many cases involving large but relatively shallow prototypes success has been dependent on the device of exaggeration of the vertical scale in comparison with the horizontal scale of the model. This is certainly true for most models of tidal waters: examples of such studies were, of course, the first true hydraulic models, and being concerned with bed movement were attempts on what is still one of the most complex of model problems. Where the containing boundary is wholly or largely moveable results 

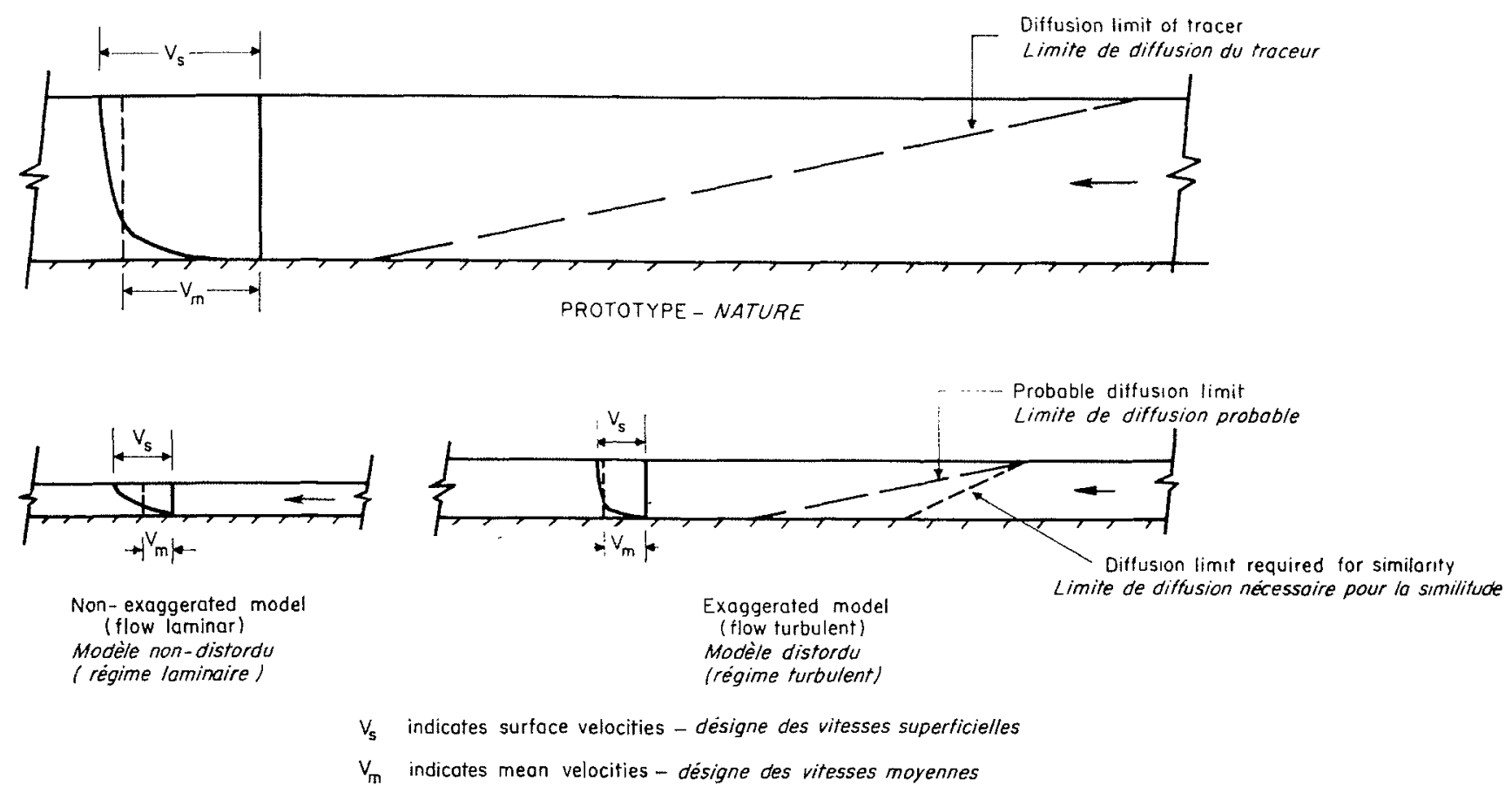

Fig. 12

Diagrammatic illustrations of the effect of exaggeration on velocity profiles and on the diffusion limits of a "tracer".

Représentation schématique de l'influence de la distorsion sur les profils de vitesse et les limites de diffusion d'un élément traceur.

still tend to be qualitative rather than quantitative, giving, say, an indication of shoaling at some point after some proposed modification rather than a close indication of the extent of the shoaling over a definite time interval. Turning to the free surface boundary we find that very close simulation of the sequence of change of water levels can be obtained throughout the length of an estuary; the containing boundary during such tests being either fixed, with its roughness determined from calibration runs, or, perhaps, mobile with a greater or lesser degree of similarity to what would obtain in the prototype under conditions corresponding to those being imposed on the model. Thus various aspects of the phenomena occuring in a prototype may be simultaneously simulated in a model with varying degree of success.

The Reynolds number criterion is normally applied to a selected length and velocity in a proposed model to check that turbulent flow will obtain. For instance, the midstream depth and velocity at the shallowest part of a model estuary might be taken. In designing a model with some minimum value of $R$ in mind it will be found that as the horizontal scale, $1 / x$, is increased, the minimum exaggeration, $x / y$ (where $1 / y$ is the vertical scale), for turbulent flow with decrease, eventually reaching the limit of one (i.e. no exaggeration). This is convenient illusration of the difference between exaggeration and distortion. Consider a flow over a more or less level bed in a prototype. By exaggerating the vertical scale of a model we may eliminate distortion of the velocity distribution, which would occur if the flow was laminar, as illustrated in Figure 12. But we can only alter and not eliminate the distortion of the strike point on the bottom of the limit of diffusion of a tracer introduced on the surface in prototype and model (also shown in Figure 12). The greater the exaggeration the greater the error of the prediction in this latter respect. In fact we will always require turbulent velocity distribution-giving, for instance, the probability of correct simulation of the travel of surface floats if we rationally scale the flows i.e. the mean velocities--but only in non-homogeneity models, where parts of the water mass is identifyable, are we likely to be interested in the diffusion of a tracer.

As regards the successful simulation of any particular aspect of the prototype conditions there are, then, several possibilities which the model designer should consider including:

(i) Useful results can be obtained over a wide range of exaggeration, and thus a small horizontal scale is feasible.

(ii) Useful results can be obtained within a 

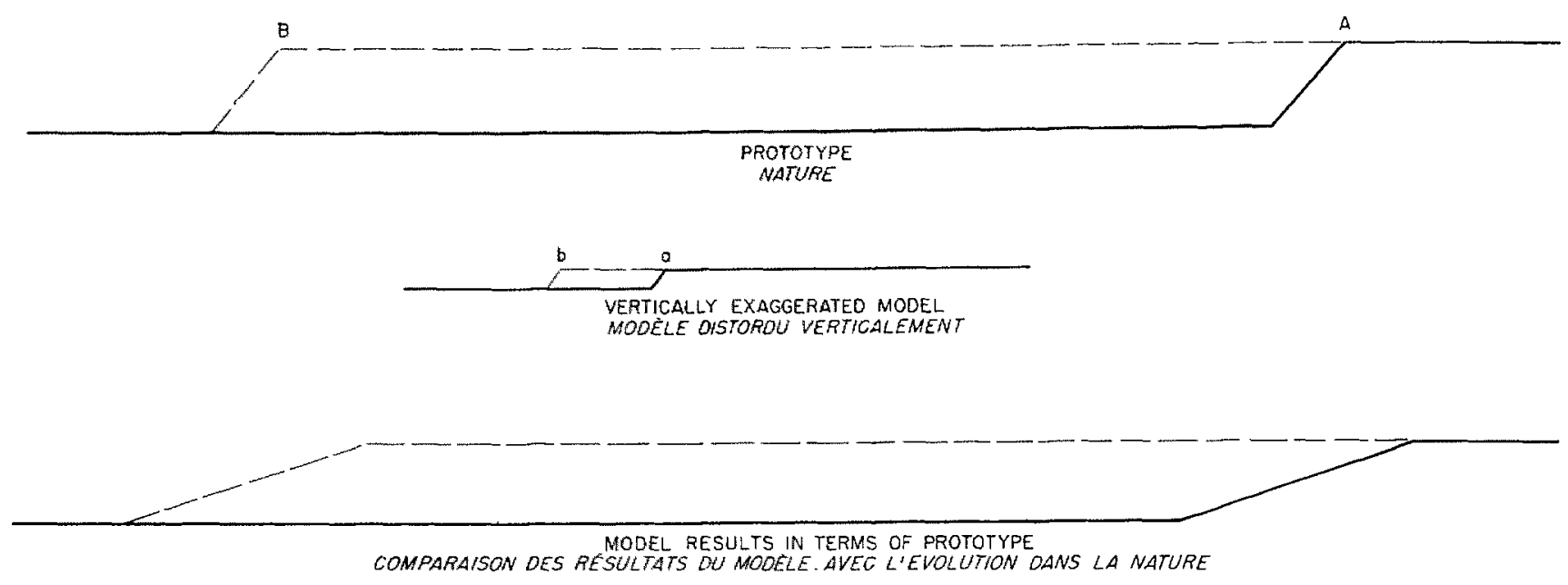

(The edge of the sand bank moves from $A$ to $B$ in the prototype and from $a$ to $b$ in the verticolly exaggerated model)

(Le bord du bone de sable se deplace de $A$ en $B$ dans vo nature et de a en b sur le modele distordu verticalement)

FIG. 13

Diagrammatic illustration of satisfactory simulation of movement of sandbank in an exaggerated model.

Schéma d'une représentation correcte du mouvement d'un banc de sable sur un modèle distordu.

restricted range of exaggeration; perhaps an upper limit might obtain or there may be a best exaggeration, with a decreasing degree of similarity at greater or lesser exaggerations. Further this best exaggeration may be related to the horizontal scale chosen.

(iii) Useful results cannot be obtained-except in a natural model-thus greatly increasing the horizontal scale if turbulent flow is to be obtained. This may well be quite uneconomic.

(iv) Useful results cannot be obtained.

It is, broadly speaking, the relative importance of vertical motions and effects as compared with horizontal motions and effects that determines the category into which some particular case is likely to fall. The angle of repose of the bed material in a loose boundary model study may impose a limit on exaggeration. But we would regard as successful a model study if it correctly predicted the overall movement of a flat topped stand bank with steeply sloping sides despite that the strict scaling up of the model bed profiles would indicate unduly gentle slopes at the edge of the prototype bank. This point is illustrated in Figure 13.

\section{Application of knowledge of exchange flow to heat dissipation models-and models involv- ing small density difference spread in general.}

The practice of using small density differences, saline or thermal, in a model is comparatively recent, the first instances known to the author occurring some twenty years ago (Tiffany, 1942; Appendix 1). Demonstrations of the type of flow which may occur where density differences are present had been made some twenty years previously (Freeman, 1929). As regards model studies it has nearly always been assumed that both the Froude and the densimetric Froude criteria should be adopted;

$$
\frac{V_{m}}{\mathrm{~V}_{p}}=\sqrt{\frac{\mathrm{H}_{m}}{\mathrm{H}_{p}}}
$$

(standard Froude number model criterion):

$$
=\sqrt{\frac{1}{y}}
$$

for an exaggerated model:

$$
\cdot \frac{\mathrm{V}_{m}}{\mathrm{~V}_{p}}=\frac{\frac{\Delta \rho_{n}}{\rho_{m}} \cdot g \cdot \mathrm{H}_{m}}{\frac{\Delta \rho_{p}}{\rho_{\bar{\nu}}} \cdot g \cdot \mathrm{H}_{p}}
$$

(densimetric Froude number criterion).

$$
\therefore \text { To satisfy both } \frac{\Delta \rho_{m}}{\rho_{m}}=\frac{\Delta \rho_{p}}{\rho_{p}}
$$

Since $\rho_{m}=\rho_{p}$ water being used in the model, $\Delta \mathrm{p}_{m}=\Delta \mathrm{p}_{p}$.

For, say, a full tidal model of an estuary the use of the Froude criterion is based on both theory - the tides being a wave effect-and 
knowledge of a number of successful investigations.

Suppose that we accept that $\Delta \rho_{m}=\Delta \rho_{p}$ and consider what best might be done to give similarity as regards the pattern of diminution of front velocities of a large prototype example of lock exchange flow in a small scale model where the horizontal scale is to be $1 / x$. We know from Figure 8 that a natural model would fail completely in this case. The device of exaggeration of the vertical scale offers a very definite improvement; so long as the breadth to depth ratio in the exaggerated model is still of the order of six or greater and we can thus ignore side effects in both model and prototype. We chose a value of $\mathrm{V} / \mathrm{V}_{0}$ and find from the congruency diagram (Fig. 8) the corresponding value of $\mathrm{L} / \mathrm{H}$ at the $\overline{\mathscr{F}_{\Delta} \mathcal{K}}$ value of the prototype. Until the diagram is extended-or possibly replaced by a similar diagram for a different exchange flow case--we must choose $\mathrm{V} / \mathrm{V}_{0}=0.9$. We then find a value of $y(1 / y$ is the vertical scale) so that:

$$
\frac{\mathrm{L} / \mathrm{H}\left(\text { model for } \mathrm{V} / \mathrm{V}_{0}=0.9\right)}{\mathrm{L} / \mathrm{H}\left(\text { prototype for } \mathrm{V} / \mathrm{V}_{0}=0.9\right)} \times \frac{x}{y}=1
$$

$\mathrm{L} / \mathrm{H}$ for the model depends on $\overline{\mathfrak{F}_{\triangle} \mathfrak{K}}$ for the model and thus upon $y$, so the process is one of a trial and error. To express this in words it is convenient to think of the device of exaggeration as rather a reduction of the horizontal scale from a chosen vertical scale. We know the actual distances at which the velocities of the prototype and model will have decreased to the chosen proportion of the respective initial velocities. The ratio of the model distance to the prototype distance is the required horizontal scale to give similarity.

The method can be ex!ended to true models by imagining that alongside the estuary, or other such large body of water with which the model study is concerned lies a channel in which occurs a lock exchange flow of the same order of magnitude as the occurrence of interest in the true prototype. This is a vital point; the order of magnitude of a saline underflow entering a river after flood clearing-as has been observed both in nature and in a model in the case of the Mississippi (Tiffany, 1942) is much greater than would be that of a local surface spread of heated water from a power station discharging condensing water to the same river. To assess the scale of the phenomenon of interest a representative depth and density difference must be estimated and a $\overline{F_{\Delta} \mathscr{R}}$ number formed.

Having decided on the horizontal scale of the real model (and hence of the imaginary model channel alongside) we find the exaggeration required in the imaginary model channel so as to give similarity with the imaginary prototype channel in respect of the exchange flow diminution of velocity pattern. This approach gave very favourable results when applied to the spread of heated water from a simplified outfall system (Barr, 1959). Both model and prototype were of laboratory size and the horizontal scale of the model was $1 / 5$.

It may be objected that this method is concerned only with the limits of spread. But to know that the limits of the spreads of a buoyant field can be reasonably well simulated in a model is a considerable step forward. The logical next step would be to examine the degree of similarity obtained in olher aspects of the exchange flow or the spread.

Model studies of the overall pattern of extension of the fronts in exchange flow-or the sequence of enlargement of the periphery of a buoyant field has been placed in catagory (ii) of the list of possible effects of exaggeration given in $2 b$. There is a best exaggeration for any particular case and any radical departure from that exaggeration will have a most detrimental effect on the value of a model study. This is not to say that the "best" exaggeration for a particular horizontal scale will necessarily give good results in a three dimensional model. There must be a further assessment of the distortion effects of the exaggeration. These are really outside of the scope of this paper although it is perhaps worth mentioning one or two points. There is possibly a partial alternative to the most obvious, and costly, remedy: to increase the horizontal scale. Some evidence has been given that in models of short lengths of estuaries-the case of many heat dissipation models - the velocities could be increased to several times those given by the Froude number criterion. The density differences must be increased corresponding; i.e. the square of the increase in velocity (Barr, 1963).

Consider the case of a discharge of buoyant water projected into a stagnant pool along a channel which is shallow in comparison with the pool, as shown in Figure 14. This is the configuration of the simplified outfall studies (Barr, 1959) referred to previously. Suppose we have a model of the situation, have chosen the vertical scale and adopt either velocities given by the Froude number criterion or some definite small multiplier with $\Delta \rho / \rho$ in adjusted accordingly. The flow per unit width of the channel is independant of the horizontal scale and if the breadth to depth ratio of the protolype is very large (say 30-50), the vertical mixing pattern on a section along the centre line of the channel will also be more or less independent of the exaggeration so long as the breadth to depth ratio in the model is still fairly large-say 6 


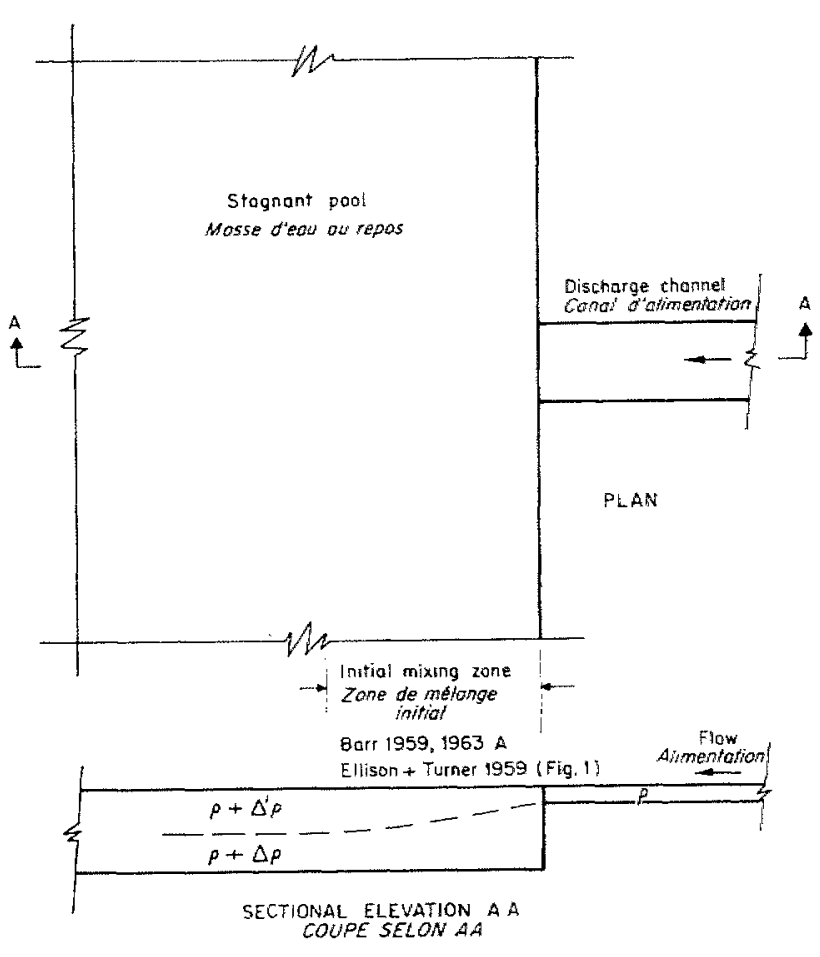

Frg. 14

Diagrammatic illustration of discharge of buoyant water into stagnant pool.

Représentation schématique

de l'injection d'une eau plas légère

dans une masse d'eau au repos.

upwards. This immediate mixing should in theory be amenable to the $\overline{\mathscr{F}_{\triangle}}$ number criterion -and there is evidence that it is (Barr, 1963). If we could accept the distortion of the short initial mixing zone implicit in choosing an exaggeration which will give simulation of the pattern of spread occurring over much longer distances, we could proceed with a model study. This is illustrated diagramatically in Figure 14. The situation, though idealised, has considerable relevance to heat dissipation studies. It will be seen that the side distortion effects must also be considered and that the breadth to depth ratio in the prototype and in the exaggerated model has a great bearing on the importance of these further distortions.

\section{GENERAL AND CONCLUSIONS}

\section{Nomenclature.}

Barr (1959) showed how markedly differential surface tension can influence a fairly small scale lock exchange overflow. A $\overline{\mathfrak{Q O}_{\Delta}} \overline{\mathfrak{g}_{\Delta}}$ or differential Weber-densimetric Froude number can be formed which can doubtless be used to determine the importance or otherwise, of surface tension distortion effects and this will be further considered in later paper. The point at issue is that it is not now possible to foresee the various combinations of gravitational (बי), differential (or densimetric) gravitational $\left(\mathscr{F}_{\Delta}\right)$ viscous $(\mathfrak{R})$, differential viscous $\left(\mathfrak{R}_{\Delta}\right)$, surface tension ( $(\mathcal{Q})$, and differential surface tension $\left(2 Q_{\Delta}\right)$ criteria which may be found relevant to particular circumstances in the future, and seems as well to have a consistant nomenclature. The $\overline{\mathscr{J}} \triangle \mathfrak{a}$ number is a criterion involving differential gravitational and viscous (not differential viscous) forces and it is suggested by the author that it should be so written. It is possible to form a differential Reynolds number taking into account differences in viscosity from point to point and $\mathfrak{R}_{\Delta}$ should be reserved for thiswhether it seems likely to ever have a practical significance or not.

An extract from a concurrent paper by the author is given as an appendix(2). Here the derivation of the $\overline{F^{\prime}} \triangle \mathscr{R}$ number is considered in full detail. In the opinion of the author these considerations are of fundamental importance in many cases where "internal" or "density current" flows are studied in models or in laboratory flumes. Whereas the $\overline{\mathscr{F}} \tilde{\mathcal{R}}$ number criterion (i.e. the simultaneous satisfaction of the standard Froude number and the Reynolds number criteria) can often be virtually neglected in normal hydraulics where it is largely possible to impose or force the flow conditions, the $\overline{\mathfrak{T}_{\Delta}} \boldsymbol{R}$ number concerns "free" conditions which cannot be externally imposed-and the implications of the relation of the $\mathscr{J} \wedge \mathcal{R}$ numbers of the compared systems can never be neglected where longitudinal spread or exchange is involved.

\section{The practical nature of the studies.}

It had seemed to the author that no logical method for the design of power station heat dissipation models existed, despite the increasing recourse to such models throughout the world, and particularly in Britain, as giving the only realistic basis for the economic choice of intake and outfall configuration in the case of steam power stations depending on tide water for condensing. A list of such model studies, showing scales and brief details, has been given by the author (Barr, 1963). Other model-studies are known to have been undertaken although no details have ever been published. The design method described here was devised during the au- 
thors period of full time research ending in late 1959. Although many obvious deficiences were apparent, mainly due to the non-existance of the very large apparatus necessary to allow the formulation of complete congruency diagrams, the method represented something tangible where nothing had previously existed; and brought at least some logic into the scaling of heat dissipation models, the use of which was inevitably continuing. In fact only one other method of scaling has, to the knowledge of the author, been suggested (Hydraulics Research 1960). This gives a scale relation with a superficial similarity to that derived from the congruency diagram approach, but appears to the author to have an unsound basis (Barr, 1963).

The next available period of uninterrupted research effort, that of the second author of the next paper in the series, was made throughout 1961, and provided an opportunity to recover the ground in both the two dimensional exchange flow experiments dealt with in the paper and in the three dimensional spread experiments intended to be of more direct likeness to the circumstances of spread of a buoyant effluent discharged from a model outfall-or, it is hoped, a full size outfall. But even in this short interval further heat dissipation models were being planned (Smith, 1962) and it was known that their scaling would have to be determined long before the benefit could be taken of the results of the further basic studies. The foregoing is intended to demonstrate the extreme practicability of the origin of the studies and to explain why it has so far appeared essential to cover as much ground as possible during any period of research time available even at the risk of superficiality.

To sum up; although some later results have been presented here for convenience, this paper (I) is primarily intended to cover the experimental work and the reasoning which, combined with that described in a recent article (Barr, 1963), allowed three large heat dissipation models to be designed in 1961 (Smith, 1962 and 1963; Barr 1963c) with some feeling of assurance (Barr, 1959) of the general logic of the method.

$$
\stackrel{*}{* * *}
$$

The experimental work was carried out in the Civil Engineering Laboratories of the Royal College of Science and Technology, Glasgow. The Author is most grateful to Professor William Frazer for the facilities granted, and for his helpful advice and criticism.

Many of the evaluations of initial velocity given in Figure 2 were made by Mr. A.M.M. Hassan under the direction of the Author.

\section{REFERENCES}

Aввот (M.B.), 1961. - La Houille Blanche No. 5, 622628 - No. 6, 827-846 (In English).

Allex (F,H.) and Price (W. A.), 1959. - The Dock and Harbour Authority 40, 465, 72-76.

Bakke (P.), 1959. - Safety in Mines Research Establishment Research Report 164.

Bann (D. I. H.), 1959. - Proc 8th Congress International Assoc. for Hydraulic Research, Paper 6-C.

BarR (D.I.H.), 1961. - The Dock and Harbour Authority, $42,494,253-258$.

Barr (D.I.H.), 1962. - Civil Engineering and Public Works Review, 57, 675, 1277-1279.

BARR (D. I. H.), 1963. - The Engineer, 215, 5587, 345-352.

BarR (D.I.H.), $1963 \mathrm{~b}$. - To be published in the proceedings 10th Congress I.A.H.R., London, 1963.

BARR (D.I.H.), 1963c. - The Engineer, 216, 5627, 885893.

Bata (G. L.), 1959. - Proc 8th Congress International Assoc. for Hydraulic Research, Paper 13-C.

Elison (T.H.) and Turner (J.S.), 1959. - J. Fluid Mech., $6,423-448$.

FreEMAN (J.R.) (editor), 1929. - Hydraulic Laboratory Practice Amer. Soc. Mech. Engineers.

HARLEMAN (D. R.), 1961. - Stratified Flow. Section 26 of Handbook of Fluid Dynamics, McGraw-Hill, N. Y.

Hydraulics Research, 1960. - H.M.S.O. Lond. (1961).

Keulegan (G. H.), 1946. - U.S. Department of Commerce, Nat. Bur. of Standards, (2nd progress report on model laws for density currents) (Unpublished).

Ketrlegan (G. H.), 1950. - Wawe Motion. Chapter 11 of Engineering Hydraulics. Wiley, N. Y.

Kevlegar (G. H.), 1957. - U.S. Department of Commerce, Nat. Bur. of Standards, Report 5168, (Unpublished).

Keulegan (G. H.), 1958. - U.S. Department of Commerce, Nat. Bur. of Standards, Report 5813, (Unpublished).

KNapp, (1942). - Proc 2nd Hydraulic Conference Univer. sity of Iowa, 289-306.

LoNG (R. R.), 1953-1955. - Tellus, 5, 42-58; $6,97-115$; 7, 341-357.

O'Brien (M. P.) and Chenno (J.), 1934. - Trans. Amer. Soc. Civil Engineers, 99, 576.

SchuF (J.B.) and Schonfeld (J.C.), 1953. - Proc. 5th Congress International Assoc. for Hydratic Research, 321-333.

Sмттн (A. A.), 1962. - The Engineer, 214, 5566, 532-535.

Tiffany, 1942. - Proc 2nd Hydraulic Congress University of Iowa, 31-50.

Yı (C.). - As reported by Keulegan (1950).

\section{APPENDIX 1}

The first instance known to the author of density differences being used in a tidal model (i.e. tides simulated in model estuary with complete tidal prism allowed for above same chosen point) was in a model of the Sacramento-San Joaquin Delta. Using a horizontal scale of $1 / 4800$ and a vertical scale of $1 / 100$ it was found that the intrusion of marked "sea water" without any density difference being used, was greater than that observed in the prototype for corresponding conditions of river flow. The addition of density differences increased the salinity intrusion, but not significantly. These control tests represent the first attempts to use small density differences in an actual tidal model (U.S. Department of the Interior, Bureau of Reclamation, Hydraulic Laboratory Report No. 155, 1944). 


\section{APPENDIX 2}

\author{
(Extract from "Spread characteristics \\ of a buoyant miscible discharge", \\ by D.I. H. Barr, 1963 b)
}

\section{The densimetric Froude-Reynolds number, $\widetilde{F_{\Delta} R}$}

The Froude number ( $\mathscr{T}$ ) and the Reynolds number $(\mathfrak{R})$ criteria can be obtained by the comparison of two geometrically, kinematically and dynamically similar systems, the prototype and the model. $\pi$ and $\mathcal{A}$ can, of course, be derived in other ways-but the above method seems most logical if consideration of the design of hydraulic models is the object. Nost model studies are concerned with homogeneous water, and the forces on corresponding elementary masses of water in model and prototype are compared; implying that the elementary mass in the prototype of density $\rho_{p}$ is surrounded by exactly similar water-of density on-and that the same holds for the model where the density is $o_{m}$. There is, however, no reason against considering the elementary masses to be small rigid objects immersed in a liquid, so long as the further limitation is made that the ratii of densities of the small object and the surrounding liquid are to be the same for prototype and model.

Rather than $g$, the gravitational coefficient, consider for a moment that the field force coefficient is $f$. There would be obtained in the usual manner:

$$
\frac{V_{p}}{\sqrt{\left(f_{p}, h_{p}\right)}}=\frac{V_{m}}{\sqrt{\left(f_{m} \cdot h_{m}\right)}}
$$

a general form of the Froude number model criterion where $V$ and $h$ are characteristic velocity and length respectively. In the same way the Reynolds number model criterion can be written:

$$
\frac{\mathrm{V}_{p} \cdot h_{p}}{v_{p}}=\frac{\mathrm{V}_{m} \cdot h_{m}}{v_{m}}
$$

where $v$ is the kinematic viscosity.

In this case concern with the flow of the liquid past the geometrically similar small objects is implied in the derivation. Rewriting:

$$
\frac{V_{p}}{V_{m}}=\frac{\sqrt{\left(f_{p} \cdot h_{p}\right)}}{\sqrt{\left(f_{m} \cdot h_{m}\right)}} \text { and } \frac{V_{p}}{V_{m}}=\frac{h_{m} \cdot v_{p}}{h_{p} \cdot y_{m}}
$$

To satisfy both:

$$
\frac{h_{m} \cdot v_{y}}{h_{p} \cdot y_{m}}=\frac{\sqrt{\left(f_{p} \cdot h_{p}\right)}}{\sqrt{\left(f_{m} \cdot h_{m}\right)}} \text { or } \frac{h_{m}^{3 / 2} \cdot f_{m}^{1 / 2}}{v_{m}}=\frac{h_{p}^{3 / 2} \cdot f_{p}^{1 / 2}}{y_{p}}
$$

$\frac{h^{3 / 2} \cdot f^{1 / 2}}{y}$ can be called the general form of the Froude-Reynolds number, $\overline{\mathscr{F}} \mathfrak{R}$.

In most treatises on hydraulic models the point is made, explicity or implicity, that in normal circumstances the field force coefficient is $g$ in both prototype and model, and that water of approximately the same viscosity obtains in both systems. To satisfy, then, the standard $\overline{\mathfrak{F} \mathcal{K}}$ number criterion

$$
\frac{h_{m}^{3 / 2} \cdot g^{1 / 2}}{\nu}=\frac{h_{p}^{3 / 2} \cdot g^{1 / 2}}{\nu} \therefore h_{m}^{3 / 2}=h_{p}^{3 / 2}
$$

and a full size "model" is necessary.

But returning to the idea of small rigid objects it would be feasible, however impracticable, to form systems consisting of hollow steel shapes immersed in liquids with the ratii of the overall densities of the objects to the densities of the liquids constant. Further suppose that the field force coefficient $f$ is equal to the vector sum of $g$ and $e$ where $e$ is the coefficient for a variable magnetic force produced by a powerful electro-magnet sufficiently remote from the experiment that variations of $e$ due to distance can be discounted. Using the general form of the $\overline{\mathscr{H}}$ R number we could obtain dynamic similarity between the systems with innumerable combinations of the three variables $h, f$ and $y$ - with the limitations only of the maintenance of geometrical similarity and of the constant ratio of the densities of each object and its surrounding liquid. There is no need, so far, to consider buoyancy directly.

Consider now a body of density $\rho_{1}$ and volume $v$ which is submerged in a liquid of density $\rho_{2}, g \cdot \rho_{1} . v$ is the downwards force of gravity on the body and $g \cdot p_{2}, v$ is the upwards force of buoyancy. The net downwards force is $g . v\left(\rho_{1}-\rho_{2}\right)$. Suppose the net downwards force be $g^{\prime} \cdot p_{1} . v$ where $g$ ' is the "effective" gravitational coefficient. Therefore

$$
g^{\prime}=g \cdot\left(o_{1}-o_{2}\right) / o_{1}
$$

and approximately equal to $g \cdot \Delta \rho / \rho$ if $\rho^{\prime}$ and $\rho_{2}$ are nearly equal. The substitution of $g^{\prime}$ for $f$ leads to $\overline{\mathscr{F}} \widehat{\mathscr{R}}=h^{3 / 2}\left(g^{\prime}\right)^{1 / 2} / \mathrm{y}$, the densimetric Froude-Reynolds number which can only be valid as a model criterion if $\Delta \rho$ is always small compared with $p_{1}$ because the ratio $\rho_{1}$ to $\rho_{2}$ must not materially alter.

The practical circumstance in which the use of the $\overline{\mathscr{T}} \mathcal{R}$ number is of great value, within the above limitation, is in density current studies and in particular in exchange flow studies, where two bodies in liquid of approximately the same density are involved. Either one may be regarded as immersed in the other, or they may, in certain cases, be thought of as mutually immersed. 


\title{
Courants de densité en canal rectangulaire
}

\author{
I. - DÉFINITIONS, CONNAisSANCES ACTUELLES, ÉtUdes SUR MOdèle
}

PAR D. I. H. BARR

\section{CAS DES ÉCOULEMENTS A FRONTS D'ONDE}

Introduction. - L'auteur rappelle les études déjà publiées sur le « lock exchange flow », que l'on pourrait appeler « onde interne d'ouverture d'écluse » (fig. $1 a$ ). Dans ce cas, deux masses (à surface libre) de liquides de masses volumiques légèrement différentes $\rho$ et $\rho+\Delta \rho$, initialement séparées par un mur vertical, sont brusquement mises en contact. On observe alors un écoulement du liquide le plus dense sur le fond (underflow) et du liquide le moins dense en surface (overflow), la vitesse initiale des deux fronts étant voisine $\left(\mathrm{V}_{0}\right)$. L'auteur rappelle ensuite que l'on étudie surtout en hydraulique des écoulements de liquides miscibles.

Nombre de Froude densimétrique, et nombre de Froude-Reynods densimétrique; $\mathscr{F}_{\triangle}$ et $\overline{\mathscr{F}} \overline{\mathcal{R}}_{\mathbf{0}}$ - Après avoir défini la gravité réduite $g^{\prime}=g \Delta \rho / \rho$, l'auteur envisage les conditions de similitude de l'écoulement considéré. Il rappelle que conserver à la fois le nombre de Froude avec gravité réduite $\left(\mathscr{G}_{\Delta}=\mathrm{V} /\left(g^{\prime} \mathrm{H}\right)^{1 / 2}\right)$ et le nombre de Reynolds $(\mathcal{R}+\mathrm{VH} / \nu)$ conduit à l'invariance du nombre de Froude-Reynolds densimétrique :

$$
\overline{\mathfrak{F}_{\Delta} \mathcal{K}}=\left(g^{\prime}\right)^{1 / 2} \mathrm{H}^{3 / 2} / \nu=\mathrm{V}_{\Delta} \mathrm{H} / \nu
$$

avec $V_{\Delta}=\left(g^{\prime} \mathrm{H}\right)^{1 / 2}$. C'est ce nombre que Keulegan appelle nombre de Reynolds densimétrique $\mathfrak{R}_{\Delta^{\prime}}$

Vitesses initiales. - La figure 2 donne les valeurs expérimentales disponibles à l'heure actuelle du rapport $\mathrm{K}=\mathrm{V}_{0} / \mathrm{V}_{\Delta}$ en fonction de $\mathrm{K} \cdot \overline{\mathcal{F}_{\triangle}} \boldsymbol{\mathcal { G }}$, pour les cas de figure représentés sur la figure 1 (seul l'écoulement correspondant à la figure $1 b$ est en charge).

La figure 4 représente, avec coloration successivement du liquide le plus dense et le moins dense (de façon à caractériser le mélange) l'overflow et l'underflow dans le cas 1 a pour une distance de parcours L à partir de la barrière égale à $18 \mathrm{H}$. La figure 5 correspond au cas $1 b$ (écoulement en charge).

Diminution de la vitesse du front. - Lorsque le front a parcouru une distance $L$, sa vitesse $\mathrm{V}$, initialement égale à $\mathrm{V}_{0}$, a diminué. Quand le canal est large, les côtés n'interviennent pas. La figure 8 correspond à ce cas et donne, pour le cas de figure 1 a, les résultats de l'auteur sous la forme imaginée par Keulegan et appelée par lui « congruency diagram». Chaque courbe correspond à une valeur donnée de $\mathrm{V} / \mathrm{V}_{0}$, l'abscisse étant $\mathrm{K} . \overline{\mathscr{F}_{\Delta}} \mathcal{\mathcal { R }}$ et l'ordonnée $\mathrm{L}_{\text {. }} / \mathrm{H}$. L'auteur pense, s'appuyant sur les expériences de Keulegan synthétisées par les figures 9 et 10, que lorsque K. $\overline{\mathfrak{F}_{\Delta}} \mathfrak{\mathcal { R }}$ croît (au-delà de 50000 ), les courbes ont tendance à devenir horizontales (indépendance de la relation entre $\mathrm{L} / \mathrm{H}$ et $\mathrm{V} / \mathrm{V}_{0}$ par rapport à $\mathrm{K} . \overline{\mathfrak{F}_{\triangle} \mathscr{G}}$ ). La figure 11 concerne l'overflow, dans le même cas $1 a$.

\section{ÉTUDE SUR MODÈLE DE CES TYPES D'ÉCOULEMENTS}

Modèles sans distorsion. - L'auteur envisage deux possibilités :

- pour un modèle court, ou pour obtenir des renseignements sur les vitesses initiales, le critère $\mathscr{T}_{\triangle}$ suffit, à condition qu'en raisonnant par analogie, on puisse montrer que la diminution de vitesse sur le parcours considéré est faible;

- lorsque la diminution de vitesse devient importante, il faudrait, sinon baser la similitude sur la conservation de $K \cdot \overline{\mathscr{F}} \Delta \mathscr{\mathcal { R }}$, du moins avoir sur le modèle des valeurs de ce nombre supérieures à $10^{5}$. Ceci est difficile dans beaucoup de cas, car on est conduit à augmenter $\Delta \rho / \rho$ sur le modèle. La limite admissible n'est pas évidente. Il semble cependant que l'on puisse aller jusqu'à 0,1 ou 0,2 . 
Utilisation de la distorsion. - L'exagération des dimensions verticales du modèle facilite le respect des conditions ci-dessus. Mais certains inconvénients en limitent l'emploi (voir fig. 12 : Diffusion d'un traceur injecté en surface). La figure 13 illustre un cas où une mauvaise représentation localisée est de peu d'importance.

Modèles représentant des phénomènes où la différence de densité est faible (en particulier : phénomènes thermiques). - L'utilisation du diagramme de la figure 8 pour déterminer par approximations successives les échelles d'un modèle distordu où les densités sont les mêmes que sur le prototype, est suggérée par l'auteur, le critère de similitude étant ici la reproduction correcte du champ des vitesses. L'auteur étudie aussi le cas (modèles courts) où l'on peut augmenter la différence de densité (et les vitesses) sur le modèle.

\section{CONCLUSION}

Après une discussion concernant les critères de similitude (il note en particulier l'influence de la tension superficielle et renvoie à l'annexe 2 où il justifie de façon détaillée l'introduction de $\overline{\mathscr{T}} \triangle \mathcal{A}$ ), l'auteur met l'accent sur l'importance du problème, surtout pour les études de refroidissement de centrales thermiques par l'eau de mers à marées.

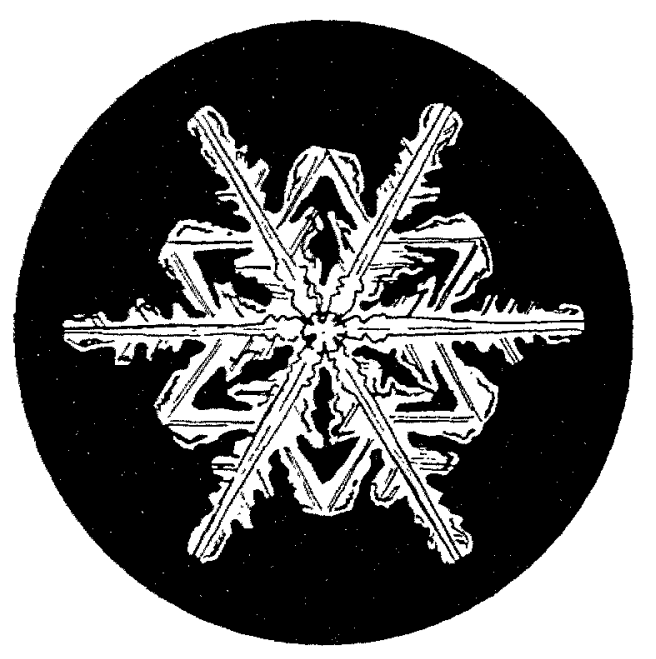

